\title{
Abnormalities in the vagus nerve in canine acrylamide neuropathy
}

\author{
PM SATCHELL, JG MCLEOD, B HARPER, AH GOODMAN \\ From the Department of Medicine, University of Sydney, Australia
}

SUMMARY Dogs exposed to acrylamide develop a sensorimotor peripheral neuropathy and megaoesophagus. The presence of neuropathy was confirmed electrophysiologically and histologically. Hindlimb motor conduction velocity was reduced and there was a loss of large diameter myelinated fibres in the dorsal common digital nerve and the tibial nerve. The conduction velocity of vagal motor fibres innervating the thoracic oesophagus was not decreased; there was a reduction in the conduction velocity of the mixed nerve action potential of the vagus. Degenerating nerve fibres were observed in the vagus in the midthoracic region. The damage to vagal nerve fibres may be an important factor in the causation of megaoesophagus.

Dogs exposed to acrylamide develop a peripheral neuropathy, the clinical features of which are similar to those observed in other species. ${ }^{1-5}$ One unique feature of canine acrylamide neuropathy is the association with megaoesophagus. ${ }^{6}$ Since an association has been reported between oesophageal dysfunction and peripheral neuropathy in alcoholic and diabetic neuropathy, ${ }^{78}$ it seemed relevant to investigate the pathophysiology of megaoesophagus in the dog exposed to acrylamide. A preliminary report of this work has been published.9

\section{Methods}

Histological and electrophysiological studies were performed on hindlimb nerves in 22 greyhounds given acrylamide orally at a dose of $7 \mathrm{mg} \mathrm{kg}^{-1} \mathrm{~d}^{-1}$. The method of administration, the animal care and the clinical findings have been described previously. ${ }^{\circ}$

\section{Neurophysiological techniques}

In the present study 45 control and 22 affected animals were used. Autonomic, histological and electrophysiological studies were carried out on 14 affected and 24 control animals, which were anaesthetised by halothane induction followed by chloralose-urethane intravenously at a dose of $50 \mathrm{mg}$ chloralose, $500 \mathrm{mg}$ urethane $/ \mathrm{kg}$. Electrophysiological and histological studies on the vagus were carried out in eight other affected animals and 21 control animals which were anaesthetised with intravenous sodium pentobarbitone at a dose of $30 \mathrm{mg} / \mathrm{kg}$. All animals were

Address for reprint requests: Dr Paul Satchell, c/o Dept of Medicine, University of Sydney, Sydney, Australia 2006.

Received 20 January 1982

Accepted 16 February 1982 intubated and ventilated with a Bird Mk8 respirator using a $50 \%$ oxygen-air mixture. Rectal temperature was maintained between $37.0^{\circ} \mathrm{C}$ and $39.5^{\circ} \mathrm{C}$ with a heating blanket.

Peripheral nervous sytem Motor conduction velocity (MCV) in the sciatic-tibial nerve was determined by stimulating at two sites and recording the electromyogram of the interosseous muscles of the hindpaw (fig 1). The sciatic nerve was exposed in the mid-thigh and the tibial nerve was exposed $2 \mathrm{~cm}$ proximal to the tuber calcanei. The nerves were stimulated supramaximally through a pair of silver wire electrodes with a $0.2 \mathrm{~ms}$ duration square wave (Devices Isolated Stimulator Mk 4). The proximal tungsten-iridium recording electrode was inserted subcutaneously over the central tarsal bones and the distal electrode was inserted over the metatarsal bones. The recording electrodes were connected to a capacitorcoupled differential input preamplifier and the output was displayed on a Tektronic 5113 Dual Beam Storage Oscilloscope. The distance between the electrodes at the hock and mid-thigh was measured to the nearest millimetre with the leg straightened but not stretched. Latency was measured on the photographic record from the start of the stimulus artefact to the onset of the first negative deflection of the muscle action potential. The amplitude of the compound muscle action potential was measured from the baseline to the peak of the negative phase of the wave.

Conduction velocity in vagal motor fibres innervating the oesophagus The conduction velocity of vagal motor fibres innervating the oesophagus was determined by stimulating the vagus supramaximally at two sites and recording the electromyogram of the lower thoracic oesophagus (fig $2 a$ ). The left cervical vagus was exposed, severed at the level of the carotid artery bifurcation and a pair of stimulating electrodes was placed on the distal stump; the vagus was kept 


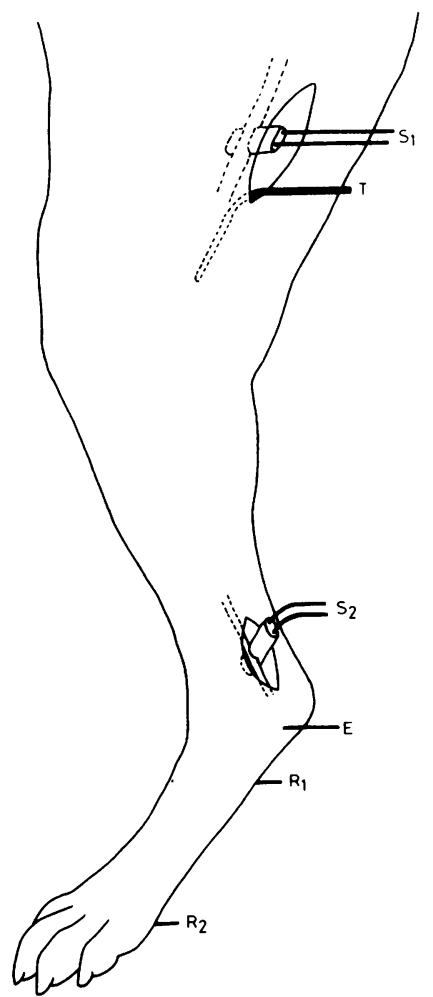

Fig 1 Electrophysiological method for determination of motor conduction velocity in the hindlimb of the dog. $S 1, S 2$, stimulating electrodes; $R 1, R 2$, recording electrodes; $T$, thermistor; $E$, earth.

in a pool of paraffin. A thoracotomy was carried out on the left side at the level of the eighth intercostal space and the vagus was mobilised as it passed under the left lung hilum; another set of stimulating electrodes was inserted around the nerve. The electromyogram was recorded in the lower thoracic oesophagus. The recording equipment was the same at that used for the determination of hindlimb MCV. Temperature was measured with a thermistor placed beside the thoracic vagus at the level of the lung hilum. Interelectrode distance was measured by placing the points

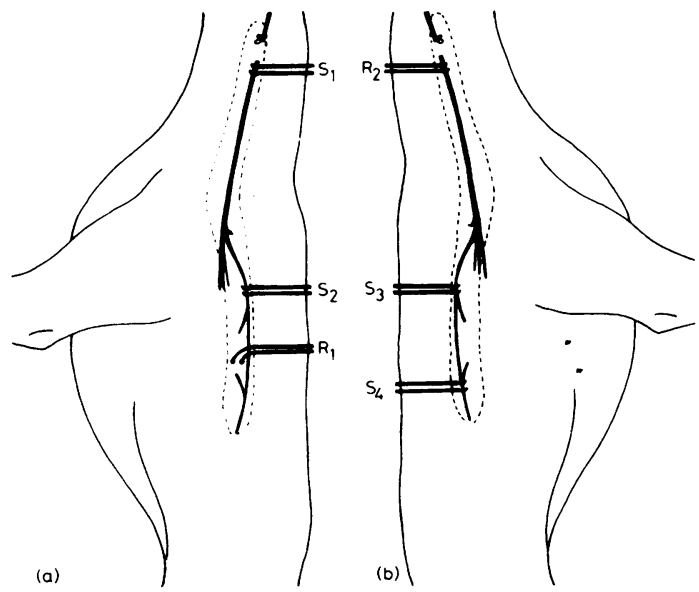

Fig 2 (a) Electrophysiological method for determination of conduction velocity in vagal motor fibres to the oesophagus. S1, pair of stimulating electrodes on cervical vagus; S2, pair of stimulating electrodes placed on vagus dorsal to the lung hilum; $R 1$, recording electrodes placed 1 cm apart on lower thoracic oesophagus. (b) Electrophysiological method for determination of vagal mixed nerve conduction velocity. S3, pair of stimulating electrodes placed on dorsal and ventral vagal branch origin; S4, pair of stimulating electrodes placed on dorsal vagal trunk origin; $R 2$, bipolar silver silver-chloride recording electrodes on desheathed cervical vagus.

of a large caliper on the distal stimulating electrode at the lung hilum and in the neck.

Conduction velocity of the mixed nerve action potential of the vagus After the nerve was sectioned, the conduction velocity of the mixed nerve action potential of the vagus (MNCV) was determined by stimulating the vagus in the chest and recording the compound nerve action potential in the cervical stump. MNCV was determined for two different lengths of the vagus. In a paraffin pool, the nerve sheath was retracted and the cervical vagus was placed on bipolar silver silver-chloride recording electrodes (interelectrode distance $=5 \mathrm{~mm}$ ). The nerve was not dissected. One pair of stimulating electrodes was placed at the

Table 1

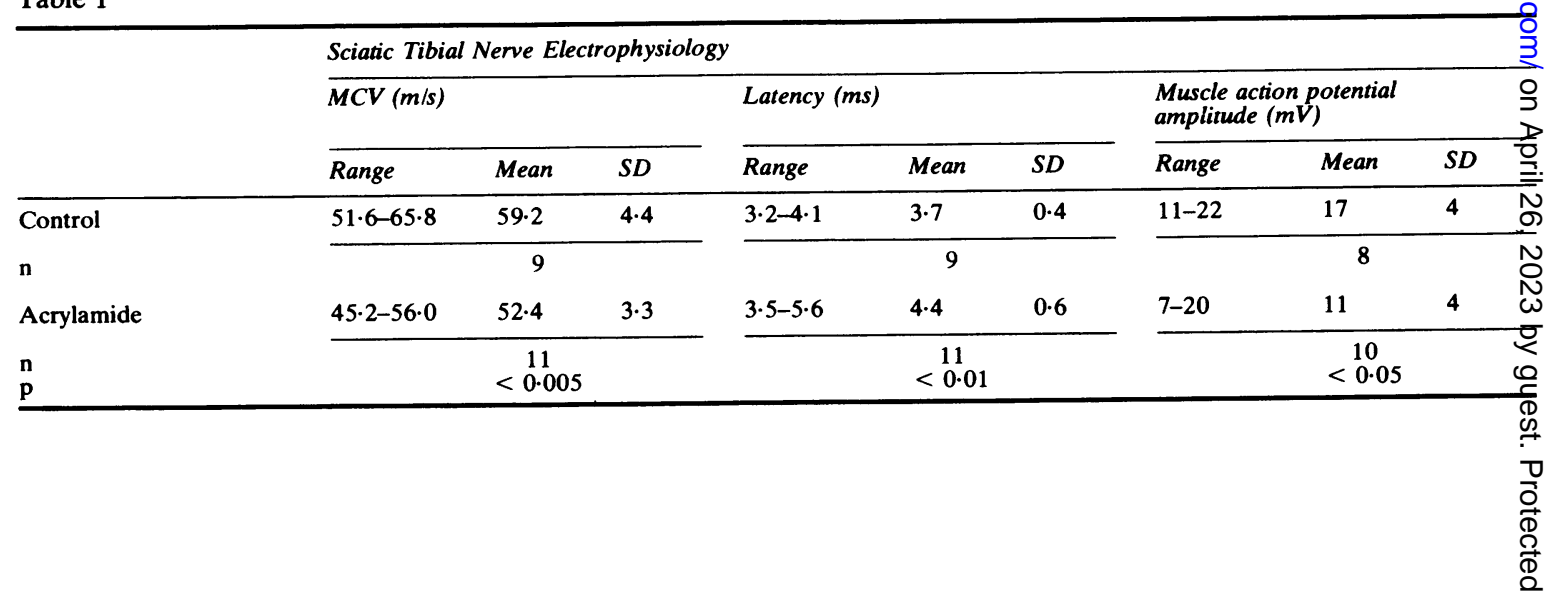


level of the lung hilum. Another pair of stimulating electrodes was placed on the dorsal vagal trunk a few centimetres above the diaphragm (fig 2b).

Each nerve was stimulated supramaximally with a $0.2 \mathrm{~ms}$ duration square wave (Devices Isolated Stimulator Mk 4), triggered at a rate of $1 / \mathrm{s}$ by a second stimulator (Pulsar 6i; Frederick Haer Co.). All responses were averaged with a PDP 11/40 computer. MNCV was determined by dividing the distance between stimulating and recording electrodes, by the latency determined from the average response of 200 stimuli.

\section{Histological techniques}

Hindlimb nerves were fixed by perfusion with $2.5 \%$ glutaraldehyde in $\mathbf{0 . 1} \mathbf{M}$ cocodylate buffer. Sections were taken from the dorsal common digital nerve and the sciatic-tibial nerve at constant anatomical sites. Histological specimens were taken from the limb opposite to that used in the neurophysiological study. The vagus was examined at three different sites; these were $1-2 \mathrm{~cm}$ caudal to the carotid bifurcation, at the level of the aortic arch, and 1-2 cm cranial to the diaphragm. The thoracic sympathetic chain at the level of the lung hilum was also examined.

All autonomic nerve specimens were immersion fixed for a minimum of 2 hours in $2.5 \%$ glutaraldehyde in $0.1 \mathrm{M}$ cocodylate buffer, followed by post fixation in Dalton's solution for 1.5 hours and then acqueous $2.5 \%$ uranyl acetate for 1.5-2 hours. The tissue was blocked in Spurr's low viscosity embedding medium after dehydration; these blocks were sectioned with an ultramicrotome (LKB Ultramicrotome or Reichert OMU3) and stained with toluidine blue. The section thickness was $1.0 \mu \mathrm{m}$. All nerve sections were photographed and complete fascicles were enlarged and printed at a final magnification of $\times 1000$. All myelinated nerve fibres were counted and measured with a TGZ3 Zeiss particle size analyser set in the exponential mode. The intrafascicular area of the nerve was measured with a Hewlett Packard 9864A Digitiser interfaced with a Hewlett Packard 9815A Calculator. The fibre diameter density histograms were calculated and plotted using a Hewlett Packard 9815A Calculator interfaced with a Hewlett Packard 9862A Calculator Plotter. The morphometric analysis employed techniques modified from those developed by Dr PJ Dyck of the Mayo Clinic, Rochester, USA.

\section{Statistical methods}

Mean values are given with the standard deviation. The significance of the difference between the groups was measured by the 2 tailed Student $t$ test, corrected for small numbers, and significance was accepted at $p<0.05$.

\section{Results}

NEUROPHYSIOLOGICAL STUDIES

Motor conduction velocity in sciatic-tibial nerves (table 1)

The distal latency recorded when the tibial nerve was stimulated ranged from 3.2 to 4.1 ms (mean, $3.7 ; \mathrm{SD}, 0.4)$ in the control animals. The distal latency in the acrylamide affected group ranged from 3.5 to $5.6 \mathrm{~ms}$ (mean, 4.4; SD, 0.6) which was significantly longer $(p<0.01)$. The mean distal latency was increased by $19 \%$.

The MCV in the tibial nerve of nine control animals ranged from 51.6 to $65.8 \mathrm{~m} / \mathrm{s}$ (mean, 59.2; SD, 4.4). The MCV in eleven acrylamide affected animals ranged from 45.2 to $56.0 \mathrm{~m} / \mathrm{s}$ (mean, $52.4 ; \mathrm{SD}$, $3.3)$, which was reduced $(p<0.005)$. The mean MCV in the acrylamide affected group was reduced by $11 \%$ compared with the control value. The mean temperature of the hindlimb measured near the stifle was $37.7^{\circ} \mathrm{C}(\mathrm{SD}, 0.5)$ in control animals and $37.5^{\circ} \mathrm{C}(\mathrm{SD}, 0.4)$ in acrylamide affected animals. These temperatures were not significantly different $(p>0.05)$.

In both control and acrylamide affected animals the compound muscle action potential recorded from the interosseus muscles of the hindpaw had a similar configuration on stimulating the tibial nerve at the ankle and the sciatic nerve at the midthigh (fig 3 ). The amplitude of the compound muscle action potential produced by stimulation of the tibial nerve at the ankle ranged from 11 to $22 \mathrm{mV}$ (mean, 17; $\mathrm{SD}, 4)$ in eight control animals compared with a range of 7 to $20 \mathrm{mV}$ (mean, 11; SD, 4) in ten acrylamide affected animals; these were significantly different $(p<0.05)$. The mean amplitude of the muscle action potential was reduced by $35 \%$ in the affected animals.

'agus Nerve Electrophysiology

\begin{tabular}{|c|c|c|c|c|c|c|c|c|}
\hline \multicolumn{3}{|l|}{$1 C V(\mathrm{~m} / \mathrm{s})$} & \multicolumn{3}{|c|}{ Hilar $M N C V(m / s)$} & \multicolumn{3}{|c|}{ Diaphragmatic $M N C V(\mathrm{~m} / \mathrm{s})$} \\
\hline :ange & Mean & $S D$ & Range & Mean & $S D$ & Range & Mean & $S D$ \\
\hline \multicolumn{3}{|c|}{12} & \multicolumn{3}{|c|}{13} & \multicolumn{3}{|c|}{9} \\
\hline $3 \cdot 9-22 \cdot 3$ & $18 \cdot 5$ & $3 \cdot 2$ & $37 \cdot 4-52 \cdot 8$ & $44 \cdot 4$ & $5 \cdot 6$ & $18 \cdot 9-37 \cdot 7$ & $23 \cdot 5$ & $7 \cdot 2$ \\
\hline
\end{tabular}



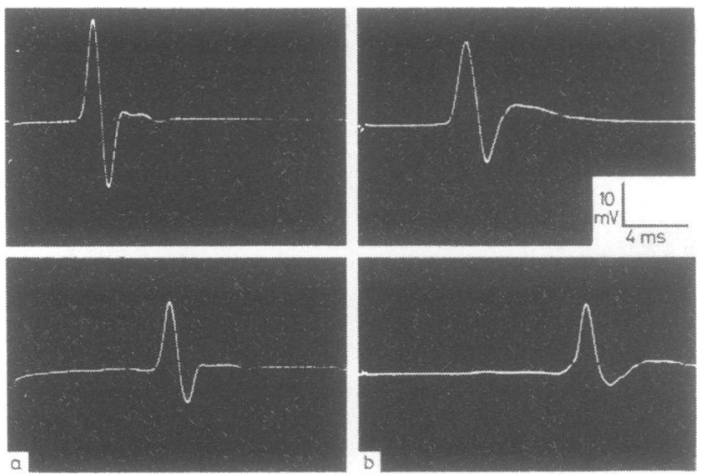

Fig 3 (a) Muscle action potential recorded from the small muscles of the hindpaw during tibial (upper) and sciatic nerve (lower) stimulation in a control animal (C11).

(b) Muscle action potential recorded from the small muscles of the hindpaw during tibial (upper) and sciatic nerve (lower) stimulation in an acrylamide affected animal (A13).

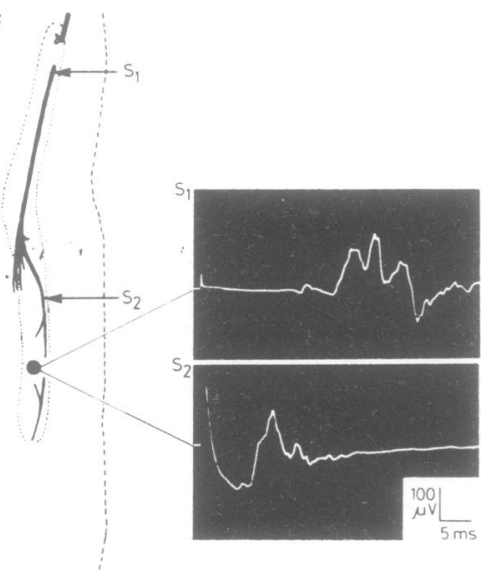

Fig 4 Typical electromyogram recorded from the lower thoracic oesophagus after cervical (S1) and hilar (S2) stimulation.

Conduction velocity in vagal motor fibres to the oesophagus (table 1)

The oesophageal electromyogram appeared identical in both groups of animals. The compound muscle action potential recorded from the lower thoracic oesophagus when the vagus was stimulated at the level of the lung hilum or the mid-cervical region was polyphasic in both groups of animals (fig 4). The motor conduction velocity ranged from $17 \cdot 2$ to $26 \cdot 2$ $\mathrm{m} / \mathrm{s}$ (mean, 20.7; SD, 2.6) in the control animals and from 13.9 to $22.3 \mathrm{~m} / \mathrm{s}$ (mean, $18.5 ; \mathrm{SD}, 3.2$ ) in the

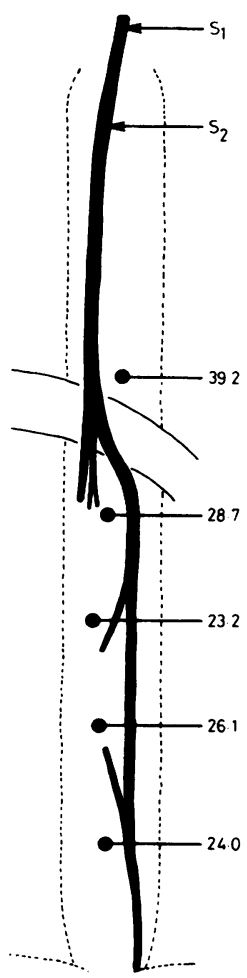

Fig 5 Variation in motor conduction velocity as the oesophageal recording electrodes were moved cranially during stimulation of the cervical vagus at two sites in a control animal (C44).

acrylamide affected animals. This difference was not significant $(p>0 \cdot 1)$. The amplitude of the responses was not compared. There was no difference in the temperature of the vagus in the two groups of animals.

In a control animal MCV was measured in vagal motor fibres innervating different regions of the oesophagus by using two sets of stimulating electrodes on the cervical vagus. It may be seen from fig 5 that the MCV in nerve fibres innervating the more proximal oesophagus tended to be greater.

Conduction velocity of the mixed nerve action potential in the vagus (table 1 )

The configuration of the compound nerve action potential recorded from the cervical vagus when the thoracic vagal trunk was stimulated supramaximally at the level of the lung hilum was similar in control and acrylamide affected animals. A large $A$ wave was always obvious (fig 6). The MNCV ranged from 42.9 to $60.0 \mathrm{~m} / \mathrm{s}$ (mean, 50.3; SD, 5.4) in the control animals. In the animals with peripheral neuropathy 
the MNCV ranged from 37.4 to $52.8 \mathrm{~m} / \mathrm{s}$ (mean, 44.4 ; SD, 5.6$)$ which was significantly slower ( $<<$ $0 \cdot 05$ ). When a well defined $C$ wave was observed conduction velocity was measured. The mean $\mathrm{C}$ wave velocity in four affected animals was $1.4 \mathrm{~m} / \mathrm{s}$; this was identical to the mean $C$ wave velocity in three control animals. The mean distance between stimulating and recording electrodes, and the mean vagal nerve temperature, were not significantly different in the control and affected animals.

When the vagus was stimulated supramaximally a few centimetres above the diaphragm a well defined compound nerve action potential was not observed. In both groups of animals there were discrete spike potentials with an amplitude of $1-2 \mu \mathrm{V}$ (fig 6). The conduction velocity of the fastest fibres ranged from 23.8 to $44.0 \mathrm{~m} / \mathrm{s}$ (mean, $33.1 ; \mathrm{SD}, 7.0$ ) in the control animals and from 18.9 to $37.7 \mathrm{~m} / \mathrm{s}$ (mean, 23.5; SD, $7 \cdot 2$ ) in the affected animals. The difference was significant $(p<0.025)$. The mean $C$ wave velocity was $1.3 \mathrm{~m} / \mathrm{s}$ in four control animals and in four affected animals. Both the mean vagal nerve temperature and the mean distance between stimulating and recording electrodes were not significantly different in the two groups of animals.

\section{HISTOLOGY}

\section{Hindlimb nerves}

In the digital nerves of acrylamide affected animals

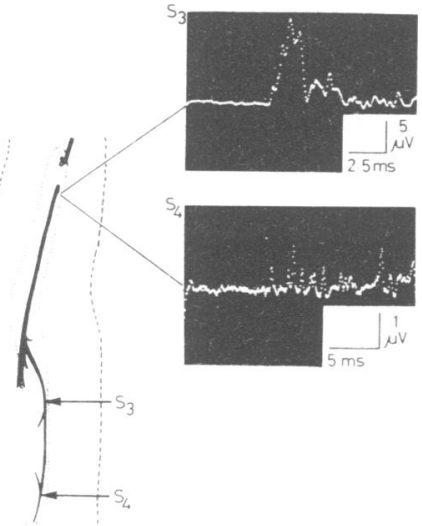

Fig 6 Typical mixed nerve action potentials recorded in the cervical vagus during midthoracic (S3) and supradiaphragmatic (S4) vagal stimulation.

there was a reduction in the total number of nerve fibres with a predominant loss of large myelinated types. Several large fibres showed degenerative changes but there was no appreciable abnormality in the small myelinated fibres (fig 7). The total myelinated fibre count in the control animals ranged from
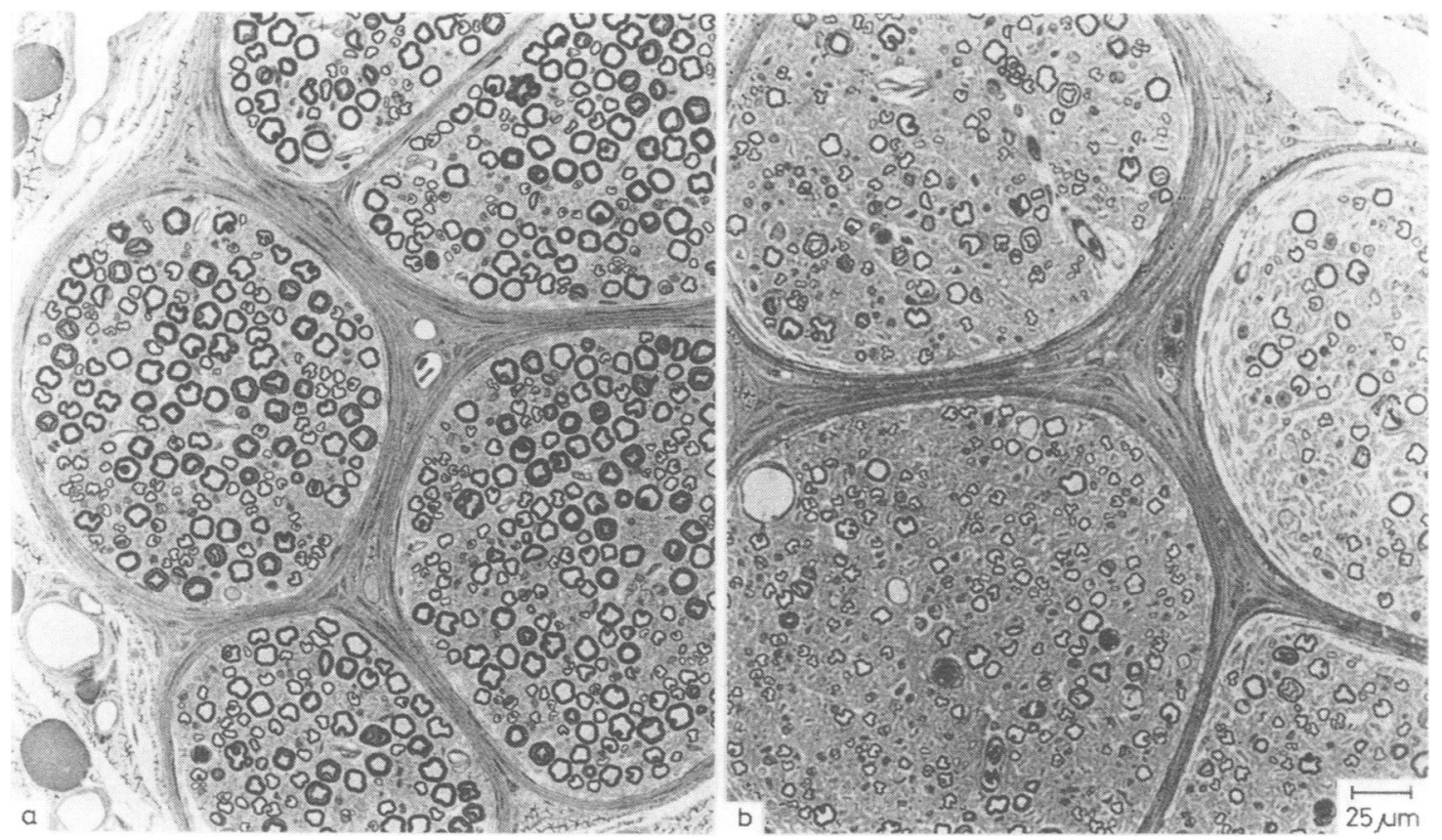

Fig 7 Digital nerves in control (a) and affected animals (b) showing the loss of large myelinated nerve fibres. 
Table 2 Nerve Histology

\begin{tabular}{|c|c|c|c|c|c|}
\hline \multirow[t]{2}{*}{ Nerve } & \multirow[t]{2}{*}{ Nerve number } & \multicolumn{2}{|c|}{ Myelinated fibre number } & \multicolumn{2}{|c|}{ Myelinated fibre density } \\
\hline & & Range & Mean & Range $\left(\mathrm{mm}^{-2}\right)$ & Mean $\left(\mathrm{mm}^{-2}\right)$ \\
\hline $\begin{array}{l}\text { Control } \\
\text { Digital nerve } \\
\text { Tibial nerve } \\
\text { Sympathetic Trunk } \\
\text { Vagus }\end{array}$ & $\begin{array}{l}3 \\
3 \\
1\end{array}$ & $\begin{array}{l}880-936 \\
6600-8493\end{array}$ & $\begin{array}{r}915 \\
7547 \\
7620\end{array}$ & $\begin{array}{l}6667-10322 \\
8305-10399\end{array}$ & $\begin{array}{r}8045 \\
9244 \\
37353\end{array}$ \\
\hline $\begin{array}{l}\text { Cervical } \\
\text { Aortic-arch } \\
\text { Diaphragm }\end{array}$ & $\begin{array}{l}1 \\
3 \\
3\end{array}$ & $\begin{array}{c}3655-5058 \\
256-632\end{array}$ & $\begin{array}{r}20154 \\
4251 \\
396\end{array}$ & $\begin{array}{l}7862-8164 \\
1035-1933\end{array}$ & $\begin{array}{r}11876 \\
8041 \\
1586\end{array}$ \\
\hline $\begin{array}{l}\text { Acrylamide } \\
\text { Digital nerve } \\
\text { Tibial nerve } \\
\text { Sympathetic Trunk } \\
\text { Vagus }\end{array}$ & $\begin{array}{l}3 \\
3 \\
1\end{array}$ & $\begin{array}{c}515-618 \\
6442-8499\end{array}$ & $\begin{array}{r}563 \\
7470 \\
5059\end{array}$ & $\begin{array}{l}5904-8729 \\
7086-10314\end{array}$ & $\begin{array}{r}7046 \\
9011 \\
28581\end{array}$ \\
\hline $\begin{array}{l}\text { Cervical } \\
\text { Aortic-arch } \\
\text { Diaphragm }\end{array}$ & $\begin{array}{l}1 \\
3 \\
3\end{array}$ & $\begin{array}{c}4165-5059 \\
202-414\end{array}$ & $\begin{array}{r}15485 \\
4603 \\
333\end{array}$ & $\begin{array}{l}3136-8247 \\
1200-1326\end{array}$ & $\begin{array}{r}13476 \\
4970 \\
1279\end{array}$ \\
\hline
\end{tabular}

880 to 936 (mean, 915) while in the affected animals the total fibre count ranged from 515 to 618 (mean, 563) (table 2.) When the mean percentage distributions of nerve fibre diameter from three control and three affected nerves were compared (fig 8a), the normal bimodal distribution was lost in the affected animals due to the reduction in the number

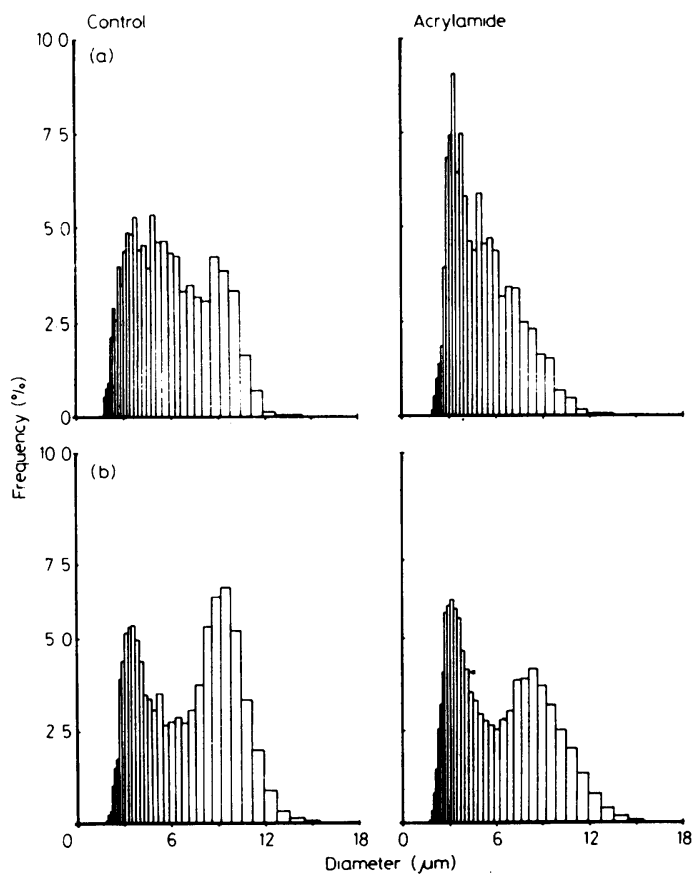

Fig 8 (a) Mean percentage distribution of myelinated nerve fibre diameter in digital nerves from three control and three affected animals. (b) Mean percentage distribution of myelinated nerve fibre diameter in the posterior tibial nerves of three control and three affected animals. of large diameter fibres. The percentage of nerve fibres greater than $9.0 \mu \mathrm{m}$ in diameter was $3.0 \%$ which was less than a third of the control percentage of $9.7 \%$.

The abnormalities in the tibial nerves were less pronounced than those in the digital nerves. The percentage distribution of myelinated nerve fibre diameter was bimodal for both groups but in the acrylamide affected animals the size of the large diameter peak was relatively reduced (fig $8 \mathrm{~b}$ ). The percentage of nerve fibres greater than $9.0 \mu \mathrm{m}$ was $10.1 \%$ in the affected animals and $18.1 \%$ in the control animals.

\section{Autonomic nerves}

Preganglionic sympathetic nerve fibres to the oesophagus were studied by examination of the thoracic sympathetic trunk at the level of the lung hilum. All specimens showed a preponderance of small myelinated fibres. There was no obvious difference between the control or the acrylamide affected nerves nor was there evidence of nerve fibre degeneration in the larger myelinated fibres. The percentage distribution of myelinated nerve fibre diameter was similar in a control and acrylamide affected animal, both being unimodal (fig 9).

In the cervical vagus, there were no degenerative changes in the larger myelinated nerve fibres in the affected animals. At the cervical level there was a bimodal distribution of nerve fibre diameter in a normal and affected animal and the percentage distributions were similar (fig 10a).

At the aortic arch level occasional degenerating nerve fibres were observed in the animals with neuropathy (fig 11). In three affected nerves the number of degenerating nerve fibres was 0,2 and 24 respectively, while degenerating nerve fibres were not observed in the control nerves. Although there 


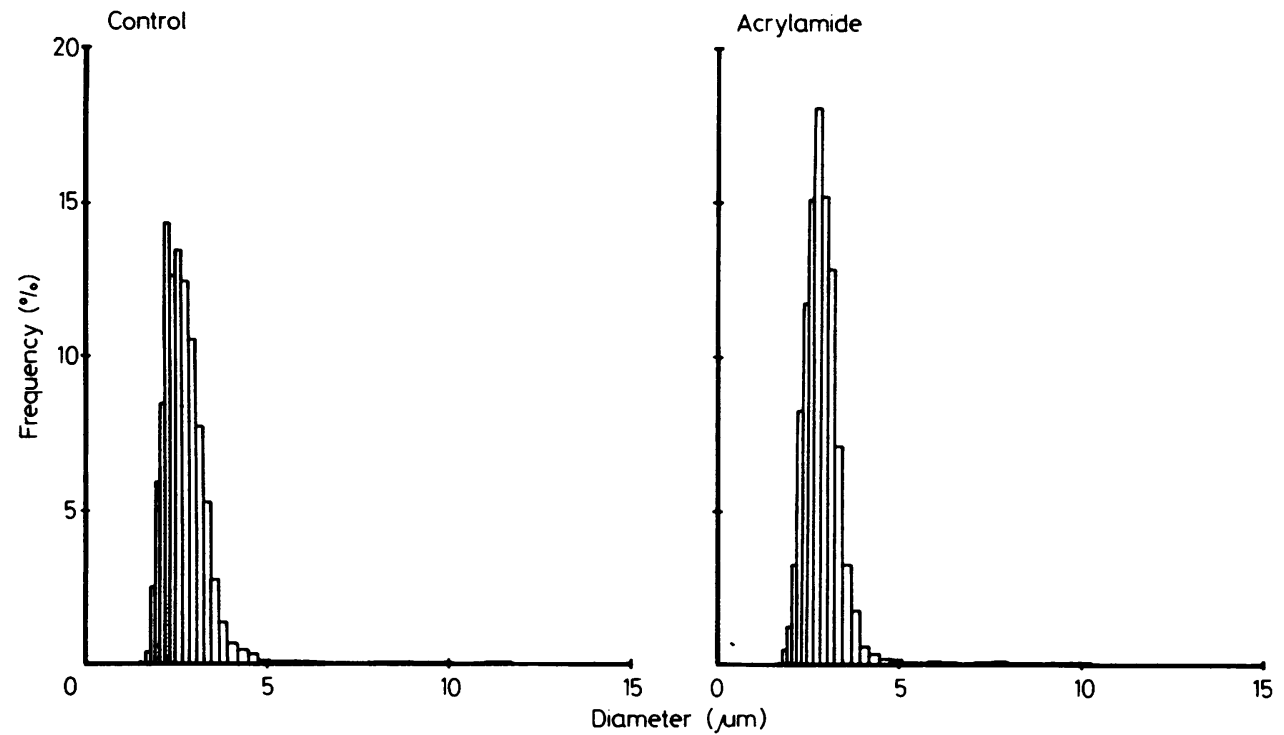

Fig 9 Percentage distribution of myelinated nerve fibre diameter of the thoracic sympathetic trunk in a control and affected animal.

was considerable variation in the density of myelinated nerve fibres throughout the vagus, the mean density of 4970 fibres $\mathrm{mm}^{-2}$ in the three affected animals at the aortic arch level was reduced compared with the mean density of 8041 fibres $\mathrm{mm}^{-2}$ in the control animals. At the aortic arch level, the mean percentage distributions of nerve fibre diameter in the three control and three affected animals were similar. The percentage of nerve fibres greater than $4.5 \mu \mathrm{m}$ in diameter was $14 \%$ in the control animals and $12 \%$ in the affected animals (fig 10b).

The vagal trunk at the level of the diaphragm was predominantly unmyelinated and degenerative changes were not observed in the larger myelinated fibres in the affected animals. The percentage distribution of myelinated fibre diameter was compared in three control and three affected animals (fig 10c). There were fewer large diameter fibres than at other levels of the vagus and the distributions appeared similar in both groups of animals. The mean number of myelinated fibres was 396 per nerve in the control animals and 333 per nerve in the affected animals (table 2). The percentage of nerve fibres greater than $4.5 \mu \mathrm{m}$ in diameter was $5.8 \%$ in the control animals and $7.0 \%$ in the affected animals.

Histological examinations of the oesophageal wall in both groups of animals at three different sites failed to reveal any differences in the appearance of the muscle layers, myenteric plexus and extrinsic nerves.

\section{Discussion}

Chronic acrylamide administration produces clinical features in the dog similar to those in other species. The mild sensorimotor peripheral neuropathy reported previously in cat, rat, primate and $\operatorname{man}^{1-5}$ is associated in the dog with megaoesophagus. ${ }^{6}$ The electrophysiological and histological changes in the peripheral nerves confirm the similarity of the neuropathy in the dog to that seen in other species where there is an axonopathy which involves both sensory and motor fibres.

In the dogs with clinical neuropathy there was a decrease in the MCV in the sciatic-tibial nerve and in the amplitude of the muscle action potential recorded from the small muscles of the foot; there was also an increase in the terminal latency. In the present study the mean value for $\mathrm{MCV}$ in the sciatic-tibial nerve of control animals was $59.2 \mathrm{~m} / \mathrm{s}$ (SD, 4.4) which was very similar to that obtained by other workers of $60.0 \mathrm{~m} / \mathrm{s}(\mathrm{SD}, 1.7)^{10}$ and $60.8 \mathrm{~m} / \mathrm{s}$ (SD, 4.9). ${ }^{11}$ The mean reduction in $\mathrm{MCV}$ in the affected dogs was $11 \%$. In man exposed to acrylamide the MCV is normal or slightly reduced. ${ }^{5}$ Hindlimb MCV in severely affected cats, rats and baboons has been reduced by $20-38 \% .^{1-312}$ Mildly affected baboons have normal values of $\mathrm{MCV} .{ }^{12}$ The configuration of the compound muscle action potential was not altered in the acrylamide affected dogs. The lack of dispersion of the compound muscle action potential has previously been observed in the 

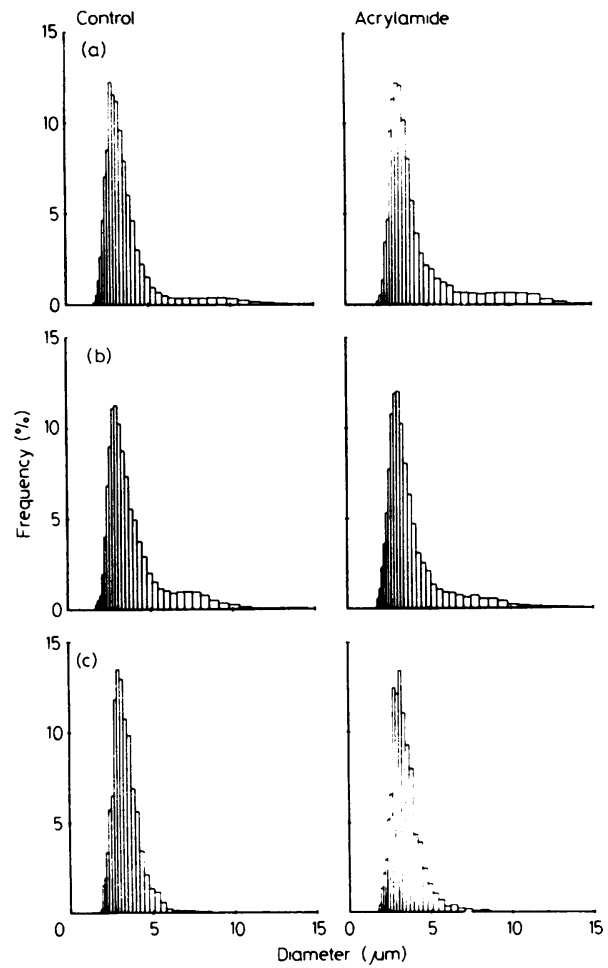

Fig 10 Percentage distribution of myelinated nerve fibre diameter of the vagus in control and affected animals.

(a) Cervical vagus, (b) Midthoracic vagus. These distributions are the mean results from three control and three affected animals, (c) Supradiaphragmatic vagus. These distributions are the mean results from three control and three affected animals.

rat, cat and baboon and is due to the absence of significant segmental demyelination in acrylamide neuropathy. ${ }^{12}$ The mean muscle action potential amplitude was reduced by $35 \%$ which may be compared with the values of $74 \%$ and $91 \%$ in severely affected baboons and cats. ${ }^{312}$ The smaller reduction observed in the present study indicates that the neuropathy in the dog was comparatively mild.

The electrophysiological studies on the sciatictibial nerve suggested that axonal degeneration of the largest nerve fibres was the predominant change in the affected dogs. The histological studies on the digital and sciatic-tibial nerve confirmed that an axonopathy affecting the largest fibres was present similar to that in other species. ${ }^{3-5}$

The conduction velocity in vagal motor nerve fibres innervating the oesophagus has not been reported previously in the dog. The only study in which the conduction velocity of motor fibres to the oesophagus has been determined is in the sheep; ${ }^{13}$ the velocity of fibres innervating the cervical oesophagus of the sheep was 15 to $30 \mathrm{~m} / \mathrm{s}$ while the velocity of fibres innervating the thoracic oesophagus was 50 to $60 \mathrm{~m} / \mathrm{s}$. In contrast the velocity of motor fibres innervating the lower thoracic oesophagus in the dog was $20 \mathrm{~m} / \mathrm{s}$ and was greater for more proximal recordings. These differences may reflect a species variation in oesophageal function. The amounts of striated and smooth muscle in the inner and outer layers of the oesophagus vary in different species. Sheep, dogs, and rabbits have predominantly striated muscle in the oesophagus. The results in the present study demonstrate that in animals with megaoesophagus the conduction velocity of motor fibres to the oesophagus was not reduced.

When the vagus nerve was stimulated at the level of the lung hilum the smooth contour of the compound nerve action potential was altered by the presence of small discrete spikes of low amplitude; these spikes represented activity in nerve fibres or bundles of nerve fibres that were in close proximity to the recording electrodes. Stimulation at both the lung hilum and the supradiaphragmatic level revealed that the conduction velocity of the fastest myelinated fibres was significantly slower in the affected group of animals. The difference in velocity was more marked when the vagus was stimulated at the more distal stimulating site. These results indicate that acrylamide damaged the fastest conducting and therefore the largest diameter nerve fibres in the midthoracic and supradiaphragmatic vagus.

In the present study the thoracic sympathetic trunk was examined since it contains sympathetic preganglionic nerve fibres innervating the oesophagus; previous studies have shown that sympathetic trunk fibres are predominantly preganglionic and the majority of them are from 1.5 to 3.5 $\mu \mathrm{m}$ in diameter. ${ }^{14}$ In the dog the modal diameter was $2.5 \mu \mathrm{m}$. In the affected animals there was no evidence of degenerative changes nor fibre loss in the sympathetic trunk. This contrasts with the reduction of myelinated fibres in the splachnic nerves of cats given acrylamide; ${ }^{3}$ these cats were more severely affected than the dogs in the present study. Since sympathectomy does not cause megaoesophagus nor does it have any effect when megaoesophagus has been produced by bilateral vagotomy in the dog, ${ }^{15}$ any minor damage to the sympathetic innervation of the oesophagus is probably of little relevance.

The vagus trunk is a major pathway for both afferent and efferent oesophageal nerve fibres. There was no evidence of nerve fibre degeneration in the vagus at the cervical level in affected animals. Degenerative changes have been seen in previous studies in the recurrent laryngeal nerve of severely 


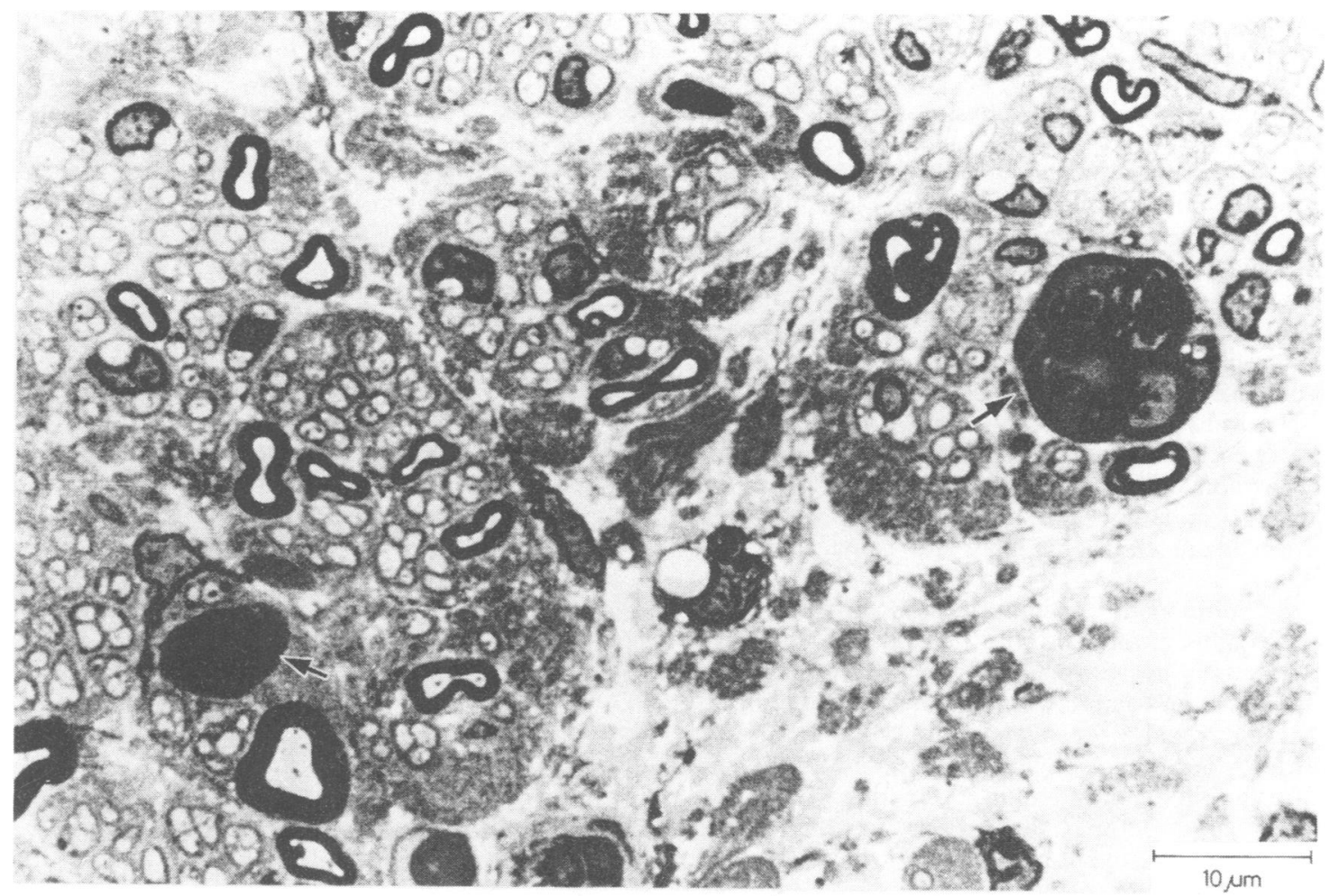

Fig 11 Vagus nerve examined at the level of the aortic arch in an acrylamide affected animal. Occasional myelinated nerve fibres (arrows) are undergoing active axonal degeneration.

affected baboons ${ }^{4}$ and in the vagus of severely affected cats; ${ }^{3}$ the absence of degenerative changes or alterations of the fibre diameter distribution in the present study was attributed to the mild degree of neuropathy. The vagus was also examined at the level of the aortic arch below the origin of the recurrent laryngeal nerve. Although the number of nerve fibres and the fibre diameter distributions appeared similar in control and affected animals the presence of some degenerating nerve fibres suggested that there was a mild axonopathy present in the affected animals. It is possible that examination of the vagus after a longer duration of neuropathy would reveal an alteration in the fibre diameter distribution. There was no evidence for axonal degeneration in the diaphragmatic vagus of affected animals. As in the cat, ${ }^{16}$ there are about 400 myelinated nerve fibres in the canine vagal trunk at the level of the diaphragm, but there is a marked reduction in the number of large diameter nerve fibres in the supradiaphragmatic vagus compared with the midthoracic region. This may explain the lack of degenerative changes. However, it is difficult to cor- relate the normal appearance of the diaphragmatic vagus with the significant reduction in conduction velocity when the vagus was stimulated at this level.

In summary, the histological studies in dogs with clinical neuropathy confirmed the presence of axonal degeneration in hindlimb nerves. Despite examination of the vagal trunk at three separate levels there were very few changes observed and there was no histological damage to the sympathetic innervation of the oesophagus. The presence of some degenerating nerve fibres in the mid-thoracic vagus provides histological evidence that there is an association between vagal nerve fibre degeneration and megaoesophagus in dogs exposed to acrylamide.

Electrophysiological and morphological studies of naturally occurring canine megaoesophagus have failed to provide a well defined pathophysiological mechanism for the disorder. Naturally occurring megaoesophagus has been attributed to neuromuscular dysfunction. ${ }^{17}$ Other studies have reported that motor function in these animals is normal, ${ }^{18-20}$ and the results of oesophageal EMG studies have been variable. ${ }^{21}$ In dogs with neuropathy and mega- 
oesophagus the oesophageal EMG has suggested denervation. ${ }^{22}$ An important variable in all these studies is the duration of megaoesophagus, as it is probable that the electrophysiological findings will be altered by the duration of oesophageal dilatation. ${ }^{18}$ The duration has been impossible to document in most studies but has been usually many months if not longer. In the present study megaoesophagus was present for a period ranging from a few days to approximately two weeks, ${ }^{623}$ and the oesophageal EMG and the conduction velocity of motor fibres to the oesophagus was similar in both groups of animals.

Naturally occurring canine megaoesophagus has not been investigated using direct nerve recording. It was noticed in one animal with this disorder that vagal stimulation did not produce apnoea as observed in control animals and damage to vagal sensory nerve fibres was inferred. ${ }^{18}$ The present study demonstrates that motor fibres to the oesophagus in animals with neuropathy and megaoesophagus are normal and that the oesophageal disorder is associated with dysfunction of the fastest thoracic vagal fibres which are visceral afferent fibres. ${ }^{24}$ Pathological changes in the distal vagus were briefly mentioned in three dogs with giant axonal neuropathy; ${ }^{22}$ there were also pathological changes in the myenteric plexus. In the dogs in the present study the plexus appeared normal. ${ }^{23}$ Vagal histology has not been examined in any other cases of experimental or spontaneous canine megaoesophagus. A more precise description of the damage to the vagal innervation of the oesophagus may be obtained when the extrinsic nerve fibres within the adventitia and outer muscle layer of the oesophagus are examined ultrastructurally.

Although it is likely that the electrophysiological and histological changes in the vagus are responsible for the production of canine megaoesophagus, a causal relationship has not been established as the origin of the affected nerve fibres in the vagus is not known. If the change in the vagus is assumed to be the primary event then it is possible to make a number of interesting predictions for cases of human peripheral neuropathy. The neuropathy induced in the present study was of the symmetrical mild sensorimotor type and it is similar in many respects to the neuropathies commonly seen in man due to alcohol, vitamin deficiency and some drug induced disorders; in some respects the disorder was similar to the symmetrical sensorimotor neuropathy of diabetes. It can be suggested from the present study that in these types of neuropathy in man there may be dysfunction of vagal afferent fibres.

Although vagal afferent fibre disturbance has been implicated in the production of the inappropri- ate antidiuretic hormone syndrome in cases of acute idiopathic polyneuritis, ${ }^{25}$ there are few symptoms or signs that can be attributed to dysfunction of these fibres in man. Some studies have reported an association between peripheral neuropathy and gastrointestinal symptoms or asymptomatic oesophageal motility disorders in diabetes. ${ }^{826}$ In alcoholic neuropathy, both vagal dysfunction ${ }^{27}$ and oesophageal motility disturbances have been described.?

The results of the present study indicate that there is damage to afferent fibres in the vagus in the experimental dying back neuropathy due to acrylamide. This finding may prove to be important in our understanding of gastrointestinal dysfunction associated with peripheral neuropathies as well as pointing to a possible site of pathophysiology in those cases of neuropathy in which unexpected death occurs.

Dr P Satcell was in receipt of a National Health and Medical Research Council Medical Postgraduate Research Scholarship.

\section{References}

' Fullerton PM, Barnes JM. Peripheral neuropathy in rats produced by acrylamide. Br J Ind Med 1966;23:210 21.

${ }^{2}$ Leswing RJ, Ribelin WE. Physiologic and pathologic changes in acrylamide neuropathy. Arch Environ Health 1969;18:22-39.

${ }^{3}$ Post EJ, McLeod JG. Acrylamide autonomic neuropathy in the cat. Part 1 . Neurophysiological and histological studies. J Neurol Sci 1977;33:353-74.

4 Hopkins AP. The effect of acrylamide on the peripheral nervous system of the baboon. J Neurol Neurosurg Psychiatry 1970;33:805-16.

${ }^{5}$ Fullerton PM. Electrophysiological and histological observations on peripheral nerves in acrylamide poisoning in man. J Neurol Neurosurg Psychiatry 1969;32:186-92.

- Satchell PM, McLeod JG. Megaoesophagus due to acrylamide neuropathy. $J$ Neurol Neurosurg Psychiatry 1981;44:906-13.

7 Winship DH, Caflish CR, Zboralske FF, Hogan WJ. Deterioration of esophageal peristalsis in patients with alcoholc neuropathy. Gastroenterology 1968;55:173-8.

- Mandelstam P, Siegel CI, Liever A, Siegel M. The swallowing disorder in patients with diabetic neuropathygastroenteropathy. Gastroenterology 1969;56:1-11.

- Satchell PM, Harper B. Altered vagal conduction velocity in dogs with acrylamide neuropathy. Proc Australian Physiological and Pharmacological Society 1981;12:6P.

${ }^{10}$ Lee AF, Bowen JM. Evaluation of motor nerve conduction velocity in the dog. Am J Vet Res 1970;31:1361-6. 
"Griffiths IR, Duncan ID, Swallow JS. Peripheral polyneuropathies in dogs; a study of five cases. J Small Anim Prac 1977;18:101-16.

12 Hopkins AP, Gilliatt RW. Motor and sensory conduction velocity in the baboon; normal values and changes during acrylamide neuropathy. $J$ Neurol Neurosurg Psychiatry 1971;34:415-26.

${ }^{13}$ Car A, Roman C. Etude des vitesses de conduction des fibres nerveuses motrices de l'oesophage. C R Soc Biol (Paris) 1965;159:1767-70.

${ }^{14}$ Ranson SW, Billingsley PR. The thoracic truncus sympathicus, rami communicantes and splanchnic nerves in the cat. J Comp Neurol 1918;29:405-39.

${ }^{15}$ Hwang K, Essex HE, Mann FC. A study of certain problems resulting from vagotomy in dogs with special reference to emisis. Am J Physiol 1947;149:429-48.

${ }^{16}$ Daly MdeB, Evans DHL. Functional and histological changes in the vagus nerve of the cat after degenerative section at various-levels. J Physiol (Lond) 1953;120:579-95.

${ }^{17}$ Gray GW. Acute experiments on neuroeffector function in canine esophageal achalasia. Am J Vet Res 1974;35:1075-81.

${ }^{18}$ Strombeck DR, Troya L. Evaluation of lower motor neuron function in two dogs with megaoesophagus. $J$ Am Vet Med Assoc 1976;169:411-4.

19 Diamant N, Szczepanski M, Mui H. Manometric characteristics of idiopathic megaoesophagus in the dog; an unsuitable model for achalasia in man. Gastroenterol- ogy 1973;65:216-23.

${ }^{20}$ Clifford DH. Lee MU, Byun KW, Lee DC. Effects of autonomic drugs on the cardiovascular system: dogs with achalasia (under halothane anesthesia). Am J Vet Res 1977;38:323-8.

${ }^{21}$ Rogers WA, Fenner WR, Sherding RG. Electromyographic and esophagomanometric findings in clinically normal dogs and in dogs with idiopathic megaesophagus. J Am Vet Med Assoc 1979;174:181-3.

${ }^{22}$ Duncan ID, Griffiths IR, Carmichael S, Henderson S. Inherited canine giant axonal neuropathy. Muscle Nerve 1981;4:223-7.

${ }^{23}$ Satchell PM, McLeod JG. Megaoesophagus and peripheral neuropathy in the dog. Proc Australian Physiological and Pharmacological Society 1979;10:289P.

24 Evans DHL, Murray JG. Histological and functional studies on the fibre composition of the vagus nerve of the rabbit. J Anat 1954;88:320-37.

${ }^{25}$ Cooper WC, Green IJ, Wang SP. Cerebral salt-wasting associated with the Guillain-Barré syndrome. Arch Int Med 1965;116:113-9.

${ }^{26}$ Hollis JB, Castell DO, Braddom RL. Esophageal function in diabetes mellitus and its relation to peripheral neuropathy. Gastroenterology 1977;73:1098-102.

${ }^{27}$ Duncan G, Johnson RH, Lambie DG, Whiteside EA. Evidence of vagal neuropathy in chronic alcoholics. Lancet 1980;2:1053-7. 